\title{
CLASICISMO, ESTÉTICA, TRADICIÓN: EL ORFEO DE JUAN DE JÁUREGUI
}

Mucho se ha escrito ya sobre la crítica de Juan de Jáuregui a la poesía de las Soledades, y no es menor el número de quienes despachan la obra poética del sevillano —en particular el Orfeo (1624) — como un mero incidente o, a lo sumo, como indicio de que su autor no pudo sustraerse al influjo de Góngora a pesar de las numerosas reservas con respecto a su estética. No pueden negarse, desde luego, algunas reminiscencias de la Fábula de Polifemo y Galatea en el poema más conocido de Jáuregui, como el pasaje del descenso al Hades, donde resuena la descripción de la caverna de Polifemo ${ }^{1}$. Sin embargo, incidencias de esa índole no bastan para declarar una filiación directa de ambas obras y estilos.

Aunque citados con amplitud, los ataques en verso al Orfeo pocas veces se recuperan con una intención más profunda que la anecdóti$\mathrm{ca}^{2}$. Sin ir más lejos, el soneto de Góngora dedicado a la ocasión abre posibilidades relevantes para el estudio de este desencuentro crítico y estético:

Es el Orfeo del señor don Juan el primero, porque hay otro segundo. Espantado han sus números al mundo por el horror que algunas voces dan.

Mancebo es ingenioso, juro a San, y leído en las cosas del profundo; pluma valiente, si pincel facundo. Tan santo lo haga Dios como es Letrán.

${ }^{1}$ Juan Matas Caballero dedica especial atención a esta semejanza en su libro Juan de Jáuregui: poesía y poética, Diputación Provincial, Sevilla, 1990, pp. 186-190; en adelante, Juan de Jáuregui: poesía y poética.

2 Ocurre así, por ejemplo, cuando Pablo Cabañas alude a esas composiciones sin añadir nada realmente revelador (véase El mito de Orfeo en la literatura española, CSIC, Madrid, 1948, pp. 148-149; en adelante, El mito de Orfeo). 
Bien, pues, su Orfeo, que trilingüe canta, pilló su esposa, puesto que no pueda miralla, en cuanto otra región no mude.

Él volvió la cabeza, ella la planta; la trova se acabó, y el auctor queda cisne gentil de la infernal palude ${ }^{3}$.

El poema es un breviario mordaz de la respuesta que la composición de Jáuregui obtuvo entre sus contemporáneos. Tanto la aparición del Orfeo en lengua castellana de Juan Pérez de Montalbán, como la recriminación por los términos del latín y del griego que adoptó Jáuregui — sin olvidar neologismos—, fueron aspectos concretos de los juicios en su contra. No obstante, al resumir la trama del poema, quizá Góngora aporta un argumento cuyas implicaciones han sido subestimadas. Antonio Carreira apunta en sus comentarios a este soneto que el poema de Jáuregui, después de que Orfeo olvida las condiciones impuestas para el regreso de Eurídice a la vida — y de su consecuente error-, consta aún de dos cantos; por ello, Góngora estaría poniendo en duda la relevancia del resto del texto, acaso anticlimático, a su parecer ${ }^{4}$. Pero lo realmente digno de notar es que Góngora, al cerrar su soneto, compara al sevillano con Cicno, hijo de Esténelo y amigo de Faetón, cuya transformación en cisne hace perpetuar sus lamentos por la muerte del transgresor imprudente que fue el hijo de Apolo ${ }^{5}$.

Este símil podría interpretarse como una acusación implícita de pérdida de perspectiva estética del autor ante asunto y obra:Jáuregui sería, entonces, un nuevo Cicno incapaz de dominar su subjetividad y concluir oportunamente el texto. Todo ello podría vincularse con la reivindicación del furor poético que Jáuregui hacía en el Discurso poético, del mismo año de 1624:

Este ardor o este arrobo tan alto compete a los grandes poetas. No es menos lo que debe el ingenio moverse y excitarse si propone a sus obras aplausos superiores. Mas debe (¿quién lo duda?), conseguir buen efecto destos ardimientos y raptos, emplearlos — digo- principalmente en conceptos sublimes y arcanos de que habla Séneca, no en lo inferior y vacío de las palabras, con que solo se enfurecen algunos ${ }^{6}$.

3 "A la fábula de "Orfeo", que compuso don Juan de Xáuregui", en Luis de Góngora, Sonetos completos, ed. Biruté Ciplijauskaité, Castalia, Madrid, 1969, p. 292.

4 Antonio Carreira, n. 11 a "A la fábula de «Orfeo", que compuso don Juan de Jáuregui”, en su edición de Luis de Góngora, Antología poética, Castalia, Madrid, 1993, p. 333. Ane Gamechogoicoechea Llopis, El mito de Orfeo en la literatura barroca española, Universidad, Valladolid, 2011, p. 125, comenta la intención satírica del soneto de Góngora.

5 Ovidio, Metamorfosis, II, vv. 367-400, $5^{\text {a }}$ ed., eds. Consuelo Álvarez y Rosa María Iglesias, Cátedra, Madrid, 2003.

${ }^{6}$ JuAn de JÁuregui, Discurso poético, ed. Melchora Romanos, Editora Nacional, Madrid, 1978, pp. 67-68; en adelante, Discurso poético. 
Jáuregui mantiene una concepción clasicista del oficio poético ${ }^{7}$. La inspiración insuflada en el poeta es la que lo conduce a la expresión de la belleza y lo sublime y, a la vez, lo aleja de lo burdo, lo cotidiano, lo prosaico. Se trata de un ser de excepción, poseedor de un estatuto distinto entre los hombres que le hace partícipe, en cierto grado, de la divinidad. Esta proclividad a la hierofanía, llevada a su límite, es la que Góngora parece censurar en el Orfeo, y apuntaría, también, al incumplimiento de Jáuregui con respecto a su reclamo constante sobre los que el sevillano juzgaba excesos lingüísticos en la poesía gongorina ${ }^{8}$.

En otras oportunidades, distintos editores y especialistas han intentado demostrar, por medio de conteos léxicos, que en el Orfeo se cumple el justo medio que proponía el sevillano, o bien, que la diferencia entre los términos elegidos por Góngora y él es casi inexistente ${ }^{9}$. La diferencia, que cualquier lector de estos poetas puede percibir, no es susceptible de enfoques cuantitativos ni estadísticas, puesto que al combinarse, las palabras originan algo más que sintagmas. Intención, sentido y significado sólo pueden apreciarse en la lectura y será siem-

7 José Manuel Rico García comenta a este respecto que: "De hecho, el furibundo ataque a las Soledades gongorinas contenido en su Antídoto, por más que se mueva continuamente en el terreno de la elocución (en particular contra las novedades léxicas y la complejidad sintáctica), es un ataque a la inventio, a lo que él creía carencia de fábula acorde al pretendido estilo ilustre del poema. De todo lo cual resulta que tan acalorado polemista fue, a la postre, un ecléctico cobijado bajo el canon clasicista, bajo una doctrina estética secular e indiscutible frente a rompedoras novedades como la gongorina" (La perfecta idea de la altísima poesía: las ideas estéticas de Juan de Jáuregui, Diputación, Sevilla, 2001, pp. 15-16; en adelante, Las ideas estéticas de Juan de Jáuregui).

${ }^{8}$ Las recriminaciones de Jáuregui a Góngora seguían este patrón: "Porque cuando quisiéramos suponer una blasfemia poética acerca de V.m. y pensar que nadie entiende versos ni los ha entendido, y que la dureza y oscuridad, que nosotros llamamos, es pura grandeza y magnificencia de estilo oculto, desengáñanos su desigualdad perruna, porque los más destos versos de las Soledades no tienen alta armonía y hinchazón de palabras, ni siempre siguen aquella oscura extravagancia de terribles frases y formas tan remotas del lenguaje común; antes, en medio de sus temeridades, se dejan caer infinitas veces con unos modos no sólo ordinarios y humildes, pero muy viles y bajos, y con versos inconstantes, y de torpe y desmayado sonido, en cuyo conocimiento no puede haber engaño" (Antídoto contra la pestilente poesía de las Soledades, ed. J.M. Rico García, Universidad, Sevilla, 2002, pp. 21-22; en adelante, Antídoto). El mismo Rico García comenta a este respecto que "Jáuregui, obviamente, no alcanzó a ver los méritos que hoy le atribuimos a los hallazgos de Góngora. Para él el lenguaje de las Soledades ni era transparente ni era persuasivo" (Las ideas estéticas de Juan de Jáuregui, p. 215).

${ }^{9}$ En el primer caso, Jack Horace Parker compara los cultismos del Orfeo y del Orfeo en lengua castellana y concluye que el de Jáuregui está más cerca del estilo de Góngora ("Lope de Vega, the Orfeo, and the estilo llano", RR, 44, 1953, pp. 3-11). Inmaculada Ferrer, por su parte, hace ver que el Orfeo y la Primera Soledad no se distinguen especialmente por la reiteración de voces cultas (Prólogo a su edición de Juan de Jáuregui, Obras: Orfeo, Aminta, Espasa-Calpe, Madrid, 1973, t. 2, p. xxix). En un plano que aparentemente puede dar más indicios sobre las actitudes poéticas que sustentan cada una de estas obras, Pablo Cabañas (El mito de Orfeo, p. 211) compara las rimas utilizadas en ellas. 
pre el juicio de un lector específico el patrón comparativo. Por ello, sería más fructífero un estudio del Orfeo en relación con la concepción que Jáuregui tenía de la escritura poética.

Al elegir a Orfeo como tema de su composición mayor, Jáuregui reivindica una figura rebelde ante la muerte que, al dejarse llevar por la impaciencia, olvida las condiciones impuestas y pierde de manera definitiva a Eurídice. La anterior podría considerarse como otra de las razones que dan sustento al soneto escrito por Góngora para denostarlo (porque el olvido de Orfeo sería homólogo al de Juan de Jáuregui con respecto a sus críticas a las Soledades). Una dimensión más positiva de su elección revela un trasunto posible del mismo Jáuregui, pues en Orfeo encontraría al artista lírico por excelencia, el mejor develador de lo sublime y sus alcances, cuya música suscita una armonía inédita a su alrededor y es capaz de conmover incluso el orden del Hades $^{10}$. Esta capacidad de subvertir la realidad es la característica más importante de la poesía para Jaúregui:

...si admitimos que sea curiosus el mago o hechicero, como prueba el erudito don Lorenzo Ramírez de Prado, diré que es hechizo y magia la industria poética, pues hace a ojos de todos de la fealdad hermosura, vende por fineza lo falso y sale destos engaños como por encanto ${ }^{11}$.

La estética que Jáuregui postula, por tanto, es capaz de reconducir la realidad por cauces distintos a los comunes, ya que es imitativa y cercana a las leyes de la objetividad. La música de Orfeo no representa la destrucción del entorno, sino el atisbo de un estado de cosas óptimo, el dominio de la armonía natural, intensificado al máximo, un breve atisbo a la comunión de los seres. Así, por ejemplo, ocurre con su canto tras la muerte de Eurídice:

\footnotetext{
Tristezas canta, que en el alma ofenden, en metros tan acordes y süaves, que el vuelo y la carrera le suspenden, condolidas, las fieras y las aves. Buscan su voz, y su terneza aprenden
}

${ }^{10}$ Juan Matas Caballero opina que "El Canto II, y parte del III, que se desarrolló en el infierno - lo cual fue motivo de numerosas burlas- representa, por tanto, una consagración de la música órfica, cuya finalidad será la de armonizar el caótico laberinto infernal. A lo largo de esos dos cantos se producirá una lucha intensa entre la armonía y la desarmonía, antitética polaridad -inherente a la estética barrocaque, en realidad, se mantiene de principio a fin del poema" (Juan de Jáuregui: poesía y poética, p. 191).

${ }_{11}$ Discurso poético, pp. 91-92. Ahí, Melchora Romanos (p. 91, n. 12) aclara que Jáuregui se refiere a la obra Penteconcarchus sive quinquaginta Militum Ductor D. Laurentii Ramírez de Prado stipendiis conductus..., cuyo autor había patrocinado la publicación del Orfeo. 
los troncos yertos, los peñascos graves;

las corrientes al métrico lenguaje

se impelen con retrógrado viaje $\mathrm{e}^{12}$.

La anterior es la primera ocasión dentro del poema en que la música y la voz de Orfeo muestran su influjo sobre el cosmos. La elección de protagonista y tema que hizo Jáuregui corresponde del todo a sus ideas sobre el papel del poeta en el mundo ${ }^{13}$. Aunque el asunto que canta Orfeo es la pérdida de Eurídice, su manifestación externa —música y voz - tiene un efecto catártico en el entorno natural, sólo posible por la comunicación entre intérprete y escuchas ${ }^{14}$. Por ello, el mito de Orfeo contiene el germen de la síntesis arte-retórica ${ }^{15}$, como ya puede verse en una de las fuentes consultadas por Jáuregui, el tratado de Giovanni Boccaccio:

12 Orfeo, I, 25, vv. 193-200, en Juan de Jáuregui, Poesía, ed. Juan Matas Caballero, Cátedra, Madrid, 1993, p. 440; en adelante, aparecerán el número de canto, estrofa y versos entre paréntesis, tras cada cita.

13 Orfeo es el primero en la acción y determina, con sus decisiones, el desarrollo del mito. Cuando cede a la atracción por Eurídice inicia toda la cadena de acontecimientos. Por medio de su canto y música, su estado anímico se manifestará sublimado para quienes lo rodean.

${ }^{14}$ Tanto esta característica de la música órfica como la índole agonística del poema provienen de la preceptiva clasicista que sigue Jáuregui. Son sólo dos rasgos de un conjunto que Aristóteles (Poética, ed. trilingüe de Valentín García Yebra, Gredos, Madrid, 1999, 1449b, 24-31), al describir el funcionamiento de la tragedia, enumera así: "Es, pues, la tragedia imitación de una acción esforzada y completa, de cierta amplitud, en lenguaje sazonado, separada cada una de las especies [de aderezos] en las distintas partes, actuando los personajes y no mediante relato, y que mediante compasión y temor lleva a cabo la purgación de tales afecciones. Entiendo por «lenguaje sazonado», el que tiene ritmo, armonía y canto, y por «con las especies [de aderezos] separadamente», el hecho de que algunas partes se realizan sólo mediante versos y otras, en cambio, mediante el canto". La particularidad de esta purificación de afectos en el poema de Jáuregui consiste, en palabras de PABlo CABAÑas, en que "la desgracia de Orfeo, personal, íntima, subjetiva, se generalizará y hará ecuménica en la Naturaleza, fiel acompañante de sus lamentaciones. Otras veces actuará sobre las cualidades personales del propio Orfeo siendo causa de efectos distintos. Así la desgracia — dolor - que le produce la muerte de Eurídice, mordida por la serpiente, acentúa, subraya, excita, engrandece su cualidad de músico y cantor, hasta el punto de enternecer a furias, ministros y dioses infernales y paralizar las penas de los habitantessombras del reino del espanto. Pero la desgracia que le produce la segunda pérdida de Eurídice, motivada por la curiosidad, actúa de modo contradictorio: debilita, ofusca, enajena, paraliza su cualidad de músico y cantor hasta el extremo de que al dirigirse a los mismos que antes enterneció, no recupera «su actividad sonora»..." (El mito de Orfeo, p. 76).

15 Gerardo Diego tenía presente esta síntesis cuando describía al poeta de esta forma: "Jáuregui, sevillano, pintor, fino catador de música, cordobés adoptivo — no por Góngora, sino por Lucano y por caballerizo — y, sobre todo, el retórico — el poético más bien- de mayor hondura y exactitud de aquella época extrema en zahorís y artesanos, en teorizantes y prácticos del bien decir, del justo, del pleno, del infalible bien decir" ("El virtuoso divo Orfeo", ROcc, 1926, núm. 14, p. 184). 
Ciertamente estas ficciones son bellas y artísticas y, para empezar por la primera, veamos por qué se le llama hijo de Apolo y de Calíope. Se llama Orfeo, casi como voz de oro, esto es la buena voz de la elocuencia que es, efectivamente, hija de Apolo, esto es de la sabiduría, y de Calíope, que se interpreta como buen sonido. Le fue dada la lira por Mercurio porque la lira, que tiene diferentes intervalos de notas, debemos entender la facultad oratoria, que no se configura con una sola voz, es decir con la demostración, sino con muchas, y una vez formada no se encuentra en todos sino en el sabio y elocuente y en el que influye por su buena voz; puesto que todas estas cosas parecen ajustarse a Orfeo, se dicen concedidas a este mismo por Mercurio, el medidor de los tiempos. Con ésta Orfeo cambia de lugar las selvas que poseen raíces muy resistentes y hundidas en el suelo, esto es a los hombres de terca opinión que, a no ser mediante las fuerzas de la elocuencia, no pueden ser apartados de su obstinación ${ }^{16}$.

Aunque Boccaccio reivindica el furor poético, su concepción del arte implica una armonía, un orden, un sistema dado, en este caso, por la retórica y la preceptiva clásica. Prescindiendo por ahora de la interpretación moral que implica esta lectura, es digna de señalarse su homologación de habilidades sociales — como la del discurso persuasivo- al virtuosismo de Orfeo; esto implica la inserción armónica del hombre en la naturaleza, y también entraña la semejanza del artista con respecto al creador de la vida, apropiación última del mito por parte de la cultura cristiana del Barroco $^{17}$.

En el poema de Jáuregui puede apreciarse, además, el apego al origen mitológico del héroe y su historia, actitud manifiesta desde el mismo título de la composición. El héroe es un epónimo en el sentido cabal del término, pues Jáuregui no redujo su versión a un relato de "hechos ficticios", como sucede cuando se antepone la frase Fábula $d e \ldots$ a los nombres de los personajes principales en el título ${ }^{18}$. Esta

16 Genealogía de los dioses paganos, V, XII, eds. M.C. Álvarez y R.M. Iglesias, Editora Nacional, Madrid, 1983, p. 321.

17 Pablo Cabañas apunta que, en El divino Orfeo de Calderón de la Barca: "Estamos asistiendo al espectáculo de la Creación encerrado en los comienzos del auto. Bajo el canto de Orfeo, bajo la voz de Dios surgen las aguas; se encarcelan las sombras; la tierra yerma, estéril, se llena de semillas, de flores, de frutos; se encienden para la eternidad dos luminarias; una de ellas presidirá la Aurora: el Sol; otra a la Noche, la Luna" (El mito de Orfeo, p. 167). El énfasis de las lecturas a lo divino sería, ya entrado el siglo XVIII, una más de las prácticas culturales rechazadas por el Neoclasicismo.

${ }^{18}$ La señal que implica titular el poema con el nombre del protagonista es inequívoca, pero al emplear el término fábula es posible también encontrar una acepción más cercana a la postura clasicista de Jáuregui: "Es preciso, por tanto, que, así como en las demás artes imitativas una sola imitación es imitación de un solo objeto, asî también la fábula, puesto que es imitación de una acción, lo sea de una sola y entera, y que las partes de los acontecimientos se ordenen de tal suerte que, si se traspone o suprime una parte, se altere y disloque el todo; pues aquello cuya presencia o ausencia no significa nada, no es parte alguna del todo" (Aristóteles, Poética, 1451a, 30-37). 
práctica, ya visible en la Fábula de Píramo y Tisbe - y presente también en la Fábula de Polifemo y Galatea-, devino en una tradición de cultivo de las versiones burlescas, donde la intención de presentar los mitos sin la solemnidad originalmente depositada en ellos —en tanto vulgata de la religión politeísta que dio sustento a la civilización clásicase basaba en estrategias como el anacronismo consciente, e hizo de la apropiación barroca de esa parte de la herencia occidental la oportunidad de convertirla en prolongación de su muy concreta realidad histórica y social. Si bien podría decirse que sería una señal más del evemerismo ya presente en la Edad Media, no resultaría menos probable que la heterogeneidad de las composiciones poéticas basadas en la mitología —implicada por esa mezcla de tonos_ no fuera sino producto de una sensibilidad en evolución, que ya había experimentado el afán del humanismo renacentista por recobrar la confiabilidad de los textos latinos y volver a las fuentes griegas, siempre glosadas, referidas de tercera mano o traducidas desde la división del imperio romano y la subsecuente caída de su fracción occidental ${ }^{19}$.

La supuesta radicalidad de la literatura barroca, su predilección por los contrastes, el uso del hipérbaton, la alusión críptica antes que la enunciación directa, entre otros rasgos, sólo puede ser tal cuando se la juzga con los parámetros de otra época, como ocurrió durante el apogeo del Neoclasicismo. Pero ya antes hubo quienes se deslindaban de prácticas que consideraban ajenas a la ortodoxia dictada por el gusto más apegado al fondo y a la forma de la estética clásica, en oposición a quienes, como Góngora, tenían siempre presente el fondo, la esencia de esa poética, y la convirtieron en punto de partida de su nueva apropiación estética de la realidad. Piénsese, por ejemplo, en una de las críticas más radicales de Jáuregui a las Soledades:

Pasemos luego a la traza desta fábula o cuento, o qué se es. Allí sale un mancebo, la principal figura que V.m. nos representa, y no le da nombre. Este fue al mar y vino del mar, sin que sepáis cómo ni para qué; él no sirve

En cambio, en el caso de los poemas de Góngora, la palabra fábula podría favorecer la concepción estética que tiende a desfamiliarizar la percepción de la naturaleza, asociándola de manera audaz con objetos en comparaciones, metáforas y símiles que desconcertaron a muchos de sus lectores, y no podían más que provocar la reacción adversa de quienes, como Jáuregui, solían ser conservadores, clasicistas, en materia estética.

${ }^{19}$ Para DÁmaso Alonso, sin embargo, la dimensión trascendental de la mitología clásica es más bien escasa: “...ese mundo cristalino y virginal no ha existido: es una fantasía, una creación del hombre, y por tanto, no es primario, sino secundario, pues supone al hombre mismo: es como una depuración, como una proyección de la triste experiencia del hombre. Es una creación, en parte religiosa y en gran parte también literaria. Esa bella nitidez es fábula, una mentira, un trampantojo de la inventora literatura. Es una bella socaliña perfeccionada a lo largo de la historia humana" (Prólogo a José María de Cossío, Fábulas mitológicas en España, Espasa-Calpe, Madrid, 1952, p. xiv; en adelante, Fábulas mitológicas). 
sino de mirón, y no dice cosa buena ni mala, ni despega su boca. Sólo hace una descortesía muy tacaña y un despropósito: que se olvida de su dama ausente, que tantas querellas le costó al salir del mar y se enamora de esotra labradora desposada en casa de su mismo padre, donde lo hospedaron cortésmente, sin que sirva aquello de nada al cuento, sino para echarlo más a perder y rematarlo sin artificio ni concierto alguno. Y, juntamente, todo el proceso del poemilla, me digan si puede ser más friático y pazguato ${ }^{20}$.

La intención en este párrafo, descontados los errores tendenciosos o por descuido $^{21}$, era intensificar la falta de correspondencia entre el tipo de estrofa elegido por Góngora y el tema al que dedica un vehículo formal usualmente vinculado a asuntos solemnes ${ }^{22}$. De ello puede concluirse, de modo provisional, que Jáuregui anteponía la poética, en tanto preceptiva, a la práctica de la poesía, al menos en el Antídoto, cuya intención era polemizar en torno a las Soledades. Desde esa perspectiva, la inmovilidad de los géneros era total para él; representaba un principio que no admitía matiz alguno. Que esto era así, desde su punto de vista, lo refleja el Discurso poético:

Lícito es y posible al ingenio, contravenir muchas veces a la regulada elocuencia y sus leyes comunes sin ofender las poéticas, antes ilustrando sus fueros. Aspirar debe a grandiosas hazañas y no medianas, porque no sólo la humildad y rendimiento es indigno en los versos, sino también la llaneza y la medianía (ya lo predica Horacio) y aunque sea pareja y sin vicios, es viciosa y tan despreciable que no halla lugar en poesía. Mas tampoco le tiene la grandeza y la sublimidad, si es pocas veces conseguida y la más alternada con precipicios. El ingenio poético presuma extremados peligros, pero no pretenda alabanza si se perdiere en ellos, que no le valdrá por disculpa lo que a Faetón: Magnis tamen excidit ausis. Pocas y leves pérdidas se le permiten, gran constancia se le encomienda ${ }^{23}$.

20 Antidoto, pp. 7-8.

21 En sus notas al pasaje citado, José Manuel Rico García examina la reductio ad absurdum que subyace a la interpretación de Jáuregui (Las ideas estéticas de Juan de Jáuregui, pp. 7-8, nn. 28-33).

22 El poema de Góngora parte del contraste entre apariencia y realidad, pues, como afirma Robert Jammes, en las Soledades, "Góngora no opone ya —o no opone solamente - a la vida de Corte un sistema de valores divertidos o incluso bufos, sino otra cosa más seria: un conjunto de valores humanos que la vida cortesana ha hecho desaparecer, y que sólo se encuentra ya entre la gente sencilla del campo" (La obra poética de Don Luis de Góngora y Argote, trad. Manuel Moya, Castalia, Madrid, 1987, p. 498; en adelante, Don Luis de Góngora y Argote). De esta forma, los atributos morales no se manifiestan asociados al prestigioso, sino a aquel tipo de vida que sí concilia discurso y realidad.

23 Discurso poético, pp. 98-99. Este pasaje podría haber dado a Góngora la pauta para la burla a Jáuregui en su soneto dedicado al Orfeo. 
Para Jáuregui, el poeta no está sujeto a las reglas de expresión, aunque su licencia para transgredirlas sólo significa que debe superar los límites impuestos para alcanzar logros estéticos mayores que aquellos considerados como modelos. Mucho pide al poeta la preceptiva, puesto que mucho se espera de él. Esta concepción agonista en torno al poeta se observa de principio a fin en el Orfeo. Baste recordar su inmunidad inicial al amor, y cómo al sucumbir a la presencia de Eurídice da inicio el devenir trágico del cantor:
Gozaba, juvenil, el trace Orfeo, de libre edad, la primavera ociosa, dando a sus años regalado empleo la lira dulcemente numerosa.
No al vínculo legal del Himeneo afectos cede, ni a la cipria diosa, cual si anteviera el ánimo presago, ya por su medio, el venidero estrago.
...
Mas, entre las beldades que atropella, de inquieta llama causador y exento, fue la excepción Eurídice más bella, que impuso apremios a su libre intento: ama, vencido, el que imperaba, y ella juzga felicidad el vencimiento. ¡Ay cuántas veces aduló, engañosa, la desdicha, con máscara dichosa!

$$
\text { (I, 1, 3, vv. 1-8, 17-24). }
$$

Orfeo tendrá como fin reestablecer la armonía perdida con cada vuelco del destino. Aunque cuando se enamora de Eurídice rompe el equilibrio que consigna Jáuregui, al hallarse correspondido recupera el balance de su estado anímico. La muerte de Eurídice supone un punto de inflexión dentro del poema, cuyas consecuencias se prolongarán desde el canto II al V. En su descenso al Hades coinciden las dos dimensiones de sentido - que se desprenden del vínculo amoroso del protagonista y de la victoria del orden sobre el caos-, mas Jáuregui, siempre atento al desarrollo de su personaje, matiza la posibilidad de una interpretación alegórica:

Riesgos tropella con audaz semblante,
anhelando desprecios de la muerte,
que si con ella lucha Amor constante,
produce Amor actividad más fuerte.
Aun hasta allí la voz del tierno amante
los peligros opuestos no divierte,
porque la causa que le impele a tanto
deba más a su esfuerzo que a su canto

(II, 36, vv. 281-288). 
Orfeo no utiliza sus habilidades líricas para facilitarse el viaje; antes bien encara los obstáculos que encuentra como simple mortal, para hacer de su aventura un mérito de amante y no el resultado de un deus ex machina que echaría por tierra la anécdota del poema narrativo. Pablo Cabañas afirma que "dentro de la mitología la predilección de los escritores se encuentra en los semidioses; hijos de un Dios y de un mortal sus hazañas se circunscriben a la vida humana, mas conservan siempre hálito de deidades"24. Cuando llega por fin al inframundo, Orfeo se abre paso con su música y subvierte la atmósfera de desolación y dolor allí reinante:

Llega a Aqueronte y en su orilla espera, las cuerdas corrigiendo y consultando.

Ve la grosera barca a la ribera opuesta conducir copioso bando.

Del instrumento y de la voz esmera, de nuevo entonces, el acento blando: gime la cuerda al rebatir del arco, y su gemido es rémora del barco.

Resonó en la ribera tiempo escaso el canto, que humanar las piedras suele, cuando atrás vuelve, y obedece el vaso más a la voz que al remo que le impele. La conducida turba, al nuevo caso, se admira, se regala, se conduele; y las réprobas almas, con aliento, se juzgan revocadas del tormento (II, 44-45, vv. 345-360).

En la acepción más directa posible, la música de Orfeo es catártica, pues su efecto se manifiesta en la conmoción de los oyentes, conscientes de su bienestar efímero ${ }^{25}$. Esa característica es más visible cuando Orfeo ya está ante Plutón. En ese momento Jáuregui invoca a las musas para indicar que ha llegado a uno de los pasajes cruciales del mito ${ }^{26}$ :

${ }^{24}$ El mito de Orfeo, p. 199.

${ }^{25}$ Véase supra, n. 13. IsABel Torres hace notar que: "This Neoplatonic idealisation of Orphic power, which locates Orphic art at the centre of a new Arcadian order, is offered to the reader as a corrective alternative to the fractured art/world vision of the Polifemo" ("Painting it safe - Juan de Jáuregui's Orfeo", en The Polyphemus complex: Rereading the Baroque mythological fable, BHS, 83, 2006, p. 95).

${ }^{26}$ Como muestra de que entre su manifestación en la poesía clásica griega y latina y su versión en la poesía castellana había una pérdida de dimensiones sagradas, Rico García recuerda que: "En la obra del poeta sevillano, nada permite pensar que el apóstrofe a las musas responde a una supuesta conformidad con la idea de la inspiración poética. Este tipo de invocaciones es un vestigio de la comunión del humanismo poético con las letras clásicas, y está muy lejos de significar el aliento de la inspiración romántica" (Las ideas estéticas de Juan de Jáuregui, pp. 71-72). 
Dime lo que lloró, cantando, Orfeo, y los efectos de su ruego, ;oh Musa!, cuando su voz, seguida del recreo, fue en el palacio cóncavo difusa, y, dulce, consiguió mayor trofeo que, acerbo, el duro rostro de Medusa; pues suspensión en piedra convertida, da a las deidades y a las piedras vida

(III, 72, vv. 569-576).

La transmutación animado-inanimado y su inversa tienen secuelas semejantes a las del discurso retórico sobre una audiencia desprevenida. Aun cuando Orfeo consigue inicialmente su propósito, al incumplir la condición impuesta para la resurrección de Eurídice, puede apreciarse que su artificio lírico pierde toda eficacia, puesto que para obtener la restitución de su esposa los dioses apelaron a su perseverancia como amante, no a su pericia artística:

Del gran dolor a la inclemencia fiera se entrega; y provocando en sí la ira, aun el tormento aseverar quisiera cuando actor de su pérdida se mira. Revuelve de Aqueronte a la ribera, y rudos forma acentos a la lira; no obedeciendo, en el turbado llanto, la cuerda al plectro, ni la voz al canto (III, 101, vv. 801-808).

Así, es posible percibir un sentido agonístico en el poema, puesto que tanto el destino como la responsabilidad del personaje sobre sus acciones le enfrentan a la adversidad de nueva cuenta ${ }^{27}$. Nada, ni su arte prodigioso siquiera, puede ya devolverle a Eurídice, pues la gracia concedida por Plutón dependía del ejercicio de su voluntad. La forma en que se sublima el dolor renovado por la pérdida lleva el tema artificio-naturaleza a su punto culminante:

Mas la nativa gracia mal se oculta, en el dolor envuelta macilento;

bella existe, y del ánimo resulta en ella impreso el interior tormento.

Así su gentileza rinde inculta

${ }^{27}$ El súbito cambio de la situación es resultado de un gesto mecánico e impensado del protagonista y, por ello, se convierte en el momento climático del poema, aún más doloroso que la muerte de Eurídice. Por lo mismo, puede considerarse que se trata de una peripecia en el sentido aristotélico, "el cambio de la acción en sentido contrario, según se ha indicado. Y esto, como decimos, verosímil o necesariamente" (Aristóteles, Poética, 1452a, 22-24). 
ninfas mil a piadoso sentimiento;

y esta piedad y femenil cuidado

que él mueve compasivo, logra amado

(IV, 106, w. 841-848).

Ocurre, en cierta forma, un retorno parcial al estado de cosas que prevalecía antes de la unión de Eurídice y $\mathrm{Orfeo}^{28}$, aunque el desinterés del músico ante las pasiones que suscita con su música está basado ahora en la fidelidad, si antes en la indiferencia. Por el contrario, la comunión del poeta con la naturaleza es completa y perfecta, no hay pasión que la contamine, y no se verá transtornada ni siquiera ante el asesinato de Orfeo:

Ya que su acuerdo, de la voz cautivo, los quietos animales restauraron, no recobrando su rigor nativo, la piedad aprendida conservaron; y muerto viendo al que adoraban vivo, de dolor, más que de furor, bramaron, cual pueden, compensando, agradecidos, dulces cantos con hórridos bramidos

(V, 173, vv. 1377-1384).

La sintonía del poeta y el orden natural perdura aun después de su desaparición, y hace necesaria, además del castigo a las Bacantes por su crimen, la integración del músico a ese ámbito empático que reflejaba de manera idónea su estado de ánimo. De ahí la catasterización de la lira órfica, que se convierte en símbolo de perduración del $\operatorname{arte}^{29}$; un arte de índole divina en el sentido pagano del mito evocado por Jáuregui, mismo sentido que tenía presente Gerardo Diego cuando afirmaba: "Atengámonos a los efectos, porque pretender apresar su divino canto — poesía y música - sería empresa casi sacrílega” 30 .

28 Para Matas Caballero, la fidelidad de Orfeo tendría una contrapartida más inmediata que el simple recuerdo luctuoso de la amada ausente: "La armonía perdida por la muerte de la amada vuelve a recuperarse a través de la música que la reconstruye proyectada en la naturaleza que participa de esa armonía melancólica. La música se convierte, pues, en el instrumento que tiene Orfeo para conseguir sus propósitos y, por lo tanto, en el elemento motriz [ sic] del mito" (Juan de Jáuregui: poesía y poética, p. 186).

29 "Luego subliman a mayor altura / la lira insigne, que, en impulso leve, / al cielo honró, creció la lumbre pura / del orbe octavo con estrellas nueve. / Al casto coro posesión segura / del nuevo signo el firmamento debe: / carácter que, en eternos resplandores, / consagra a nueve Musas nueve honores" (V, 179, vv. 1425-1432).

30 "El virtuoso divo Orfeo", p. 194. Para José María de Cossío, "La música bate sus alas sobre los versos, y el poeta nos describe la mecánica del instrumento, o los efectos en los oyentes, pero nada sustantivo nos dice de ella, aunque su presencia armoniosa se presiente en cada verso" (Fábulas mitológicas, p. 406). 
La huella de la inefabilidad, como señala Gerardo Diego, es patente en el poema, pues intentar describir la música en sí haría naufragar el texto de Jáuregui. Pero tan importante como la trascendencia del artista es el cumplimiento de su destino, cuyos presagios ya indicaban que, al menos en vida, la suerte de Orfeo y Eurídice sería trágica. Cabría discutir si esta limitación constante de la poesía en el Orfeo obedece al deseo de respetar esa esfera de lo indecible en la que ni siquiera el poeta puede penetrar, a riesgo de fracasar. Parece, de cualquier modo, que se trata de uno de los momentos en que Jáureguipoeta desmiente con su proceder a Jáuregui-polemista y, sobre todo, a Jáuregui-preceptor ${ }^{31}$. Si Orfeo representaba para Jáuregui la figura que encarnaría la máxima aspiración artística, la trascendencia del músico tendría la misma importancia que el cumplimiento de su destino, en términos del programa estético que se proponía el sevillano. El tránsito de Orfeo cumple definitivamente un sino predeterminado, y le conduce a una vida otra:

En los Elíseos reinos colocado, a Eurídice investiga cuidadoso, cuando su vista le atajó el cuidado, y fue su vista el colmo a su reposo. Burlando ya de la invasión del hado, en sus abrazos se internó glorioso, donde anteriores padecidos males hoy le sazonan gozos inmortales

(V, 186, vv. 1481-1488).

En esta doble conciliación final, arte y vida cumplen su paso por el mundo y concretan, en el texto del poema, la aspiración de su autor a una estética de la armonía, la conjunción de los efectos hacia un objetivo único, la concordancia entre forma y discurso y la contención como sola vía para dar cauce a lo sublime ${ }^{32}$. Juan Matas Caballero se detie-

31 Fernando Gómez Cabia señala que “...por un lado va el crítico clasicista, que harto tiene con su difícil baile en el filo; y por el otro el poeta, inconsciente, desde la seguridad creativa de la poesía nueva, de los riesgos y abismos de una teorización límite" ("Retorización de la poética, poetización de la retórica e hipertrofia de la elocutio. Sobre el Discurso poético de Juan de Jáuregui”, en Quintiliano: historia y actualidad de la retórica. Actas del Congreso Internacional..., eds. Tomás Albaladejo, Emilio del Río y José Antonio Caballero, Gobierno de La Rioja-Instituto de Estudios Riojanos-Ayuntamiento de Calahorra, Logroño, 1998, t. 2, p. 615). Concuerdo en lo sustancial con esta afirmación, por cuanto ninguna teoría puede dar cuenta de una realidad de manera total. Ello sin descartar que, para el clasicismo de Jáuregui, todas las opciones asumidas al caracterizar a Orfeo concuerdan con su tentativa de ceñir la poesía a lo sublime.

32 "La reafirmación barroca del Orfeo se pone una vez más de manifiesto desde el instante en que se observa la amplificación en el tratamiento del tema de la música y el de la naturaleza, que se traduce en la superposición de lo artificioso, es decir, lo musical, sobre lo natural, ya que — como se ha visto- el concierto de Orfeo ha 
ne a considerar que Jáuregui, con respecto a la estética expresada en el Orfeo,

...no podía caer en una hipertrofia del elemento verbal en detrimento de los contenidos, ni en dificultar la forma poética hasta provocar la incomprensión, puesto que en este aspecto se basaba buena parte de su crítica y, aunque el tema así lo requiriese, no podía dar más facilidades a sus enemigos; y, por otra parte, quizás convenga tener en cuenta que, tal vez, la mejor manera de demostrar el carácter musical del Orfeo y los efectos catárticos derivados de su héroe lírico fuera expresándolo mediante una adecuada contención formal ${ }^{33}$.

Excesivamente programático, quizá ${ }^{34}$, Jáuregui sólo pudo haber recibido la acusación de incongruencia en un medio donde sus polémicas críticas a Góngora permanecían en el recuerdo de cuantos continuaban involucrados en el debate sobre poesía culta y poesía llana ${ }^{35}$. Para Francisco Javier Álvarez Amo, ese ambiente hace comprensibles las reacciones de Jáuregui al prestigio de Góngora y la respuesta crítica a su Orfeo:

La trayectoria de Jáuregui ilustra, más bien, el carácter sistemático de la República de las Letras en el Siglo de Oro. El valor de las posiciones individuales depende de, y repercute sobre, el valor de la posición del

provocado la transformación de la propia naturaleza cuya humanización - e, incluso, solidaridad espiritual con el artífice melódico- ha sido el resultado final de ese proceso. La música se nos presenta, pues, como el instrumento sobre el que se sustenta la nueva armonía natural, con lo que el poeta retoma la idea de la filosofía pitagórica y neoplatónica que reafirma la unidad de toda la naturaleza que forma, a través del concierto de Orfeo, una armonía universal" (Juan de Jáuregui: poesía y poética, pp. 208209). En la supremacía del arte sobre la naturaleza que señala MATAS CABALLERo probablemente sería más sensato observar una prolongación de la naturaleza en el arte.

${ }^{33}$ Juan de Jáuregui: poesía y poética, p. 196.

34 Para Rico García, "Jáuregui no transigió con ninguna de las justificaciones de la oscuridad. La intolerancia que exhibió en su Discurso fue la causa de que muchos puntos de su argumentación fueran muy pobres críticamente. No parece lógico que no hallara en la poesía de su tiempo modelos que representaran el ideal de poesía perspicua que propugnaba teóricamente. Frente a la degradación de los «modernos» que él describe, propone los ejemplos a seguir de Lucrecio, Manilio, Arato y Santo Tomás" (Las ideas estéticas de Juan de Jáuregui, p. 160). ANTONio García Berrio recuerda que “...el defecto capital de la Poética clasicista [... es] su desprecio por la consideración del tránsito del gusto artístico hacia nuevos derroteros" (Preliminar a su libro Introducción a la poética clasicista: Cascales, Planeta, Barcelona, 1975, p. 28). El conservadurismo estético de Jáuregui se debe, pues, a su predilección por la opción clásica.

35 Recuerda Rico García que "Jáuregui no dudó sobre la identidad del inspirador de la campaña urdida en su contra. Él tenía la certidumbre de que los doctores y licenciados que titulaban los escritos dirigidos contra su Orfeo, todos, eran uno: Lope. Su respuesta a las acusaciones se materializó en la Carta del licenciado Claros de la Plaza al maestro Lisarte de la Llana, carta censoria en la que se denunciaba el abuso de los cultismos en la Jerusalén de Lope. Respondía, pues, haciendo lo que mejor sabía: contender" (Las ideas estéticas de Juan de Jáuregui, p. 225). 
resto de individuos. Cualquier alteración del campo da lugar a casi imprevisibles efectos de acción y reacción. La azarosa carrera de Jáuregui debe así muchas de sus vicisitudes a circunstancias históricas que, en principio, poco tenían que ver con él: el irresistible ascenso de Luis de Góngora, desde la difusión de sus obras mayores hasta su aterrizaje en el Madrid cortesano hacia 1617; la privanza de Olivares y la situación de privilegio de su partido sevillano; la disminución del prestigio relativo de Lope de Vega entre los aristócratas madrileños; etc. La trayectoria de Jáuregui deja, de esta forma, de contener misteriosos e inexplicables virajes a favor y en contra de Luis de Góngora o Lope de Vega: sus acciones y omisiones, en efecto, como las del resto de sus contemporáneos, como las de los nuestros, nacen del conflicto entre sus aspiraciones individuales y las coordenadas poéticas de su tiempo ${ }^{36}$.

De la anterior consideración del ámbito literario español del siglo XVII se desprende la interrelación de los poetas y sus simpatizantes con los patrocinadores de las letras y los políticos que podían darles cabida en la administración del reino, o bien convertirse en sus mecenas. Al tomar en cuenta este factor, las distintas etapas de la evolución de Jáuregui dentro del sistema literario se hacen más comprensibles ${ }^{37}$. Aunque en el Orfeo es recurrente el empleo de cultismos e hipérbatos, la impresión que deja en el lector es bien distinta de la que se desprende de un poema como las Soledades ${ }^{38}$. Mientras que en este último no hay una relación directa entre asunto y forma, en el poema de Jáuregui, asunto elevado y forma —el endecasílabo en octavas realeshablan de su intención de elitismo basado en la preceptiva clasicista ${ }^{39}$ :

36 “«Yo no presumo de poeta...»: la trayectoria de Juan de Jáuregui”, Etiópicas. Revista de Letras Renacentistas, 2011, núm. 7, p. 138.

37 “...don Gaspar de Guzmán, convertido ya en Conde-Duque de Olivares y figura dominante en la corte y la política españolas. Su ascenso en la corte, con la subida al trono de Felipe IV (1621) y en la proximidad de la aludida salida frustrada del Panegírico, significó también la promoción de algunos poetas del círculo sevillano, como Jáuregui y Rioja, elogiosamente citados por nuestro autor" (PEDro Ruiz Pérez, "Una respuesta al Panegírico por la poesía. Esbozos de crítica en la Andalucía barroca", NRFH, 54, 2006, p. 457). Agradezco a Martha Elena Venier haberme sugerido la lectura de este artículo.

38 Si se trata de un asunto de mera percepción o de un hecho que ameritaría mayor detenimiento para dilucidar en qué sentido sería sensato pronunciarse, lo cierto es que las críticas de Jáuregui a Góngora pesan sobremanera al considerarlo.

39 Podrá argumentarse, acaso, que el párrafo anterior no propone una distinción real entre ambos poetas y que minimiza a Góngora, mas puede decirse a su favor que tiene presente esta conclusión de Robert Jammes: "El estilo de las Soledades no es, en el fondo, más que el caso límite de un proceso extraordinariamente frecuente en su época en España y en otros sitios, y que desemboca siempre en lo rebuscado y refinado: en la medida en que el poeta se siente decepcionado por la vida cortesana, se ve obligado a maldecirla y a hacer el elogio de la vida rústica; pero en la medida en que él mismo está ligado, y no solamente por la ideología, a la aristocracia, su huida de la corte no puede desembocar en un «retorno al pueblo». Por el contrario, lo que el poeta opone, la mayoría de las veces, a la vida tumultuosa e incierta de la 
Es cierto que la obra excelente no puede ser estimada en su justo valor menos que por otro sujeto igual a quien la compuso. Todos los inferiores defraudan su precio por no alcanzarle, aunque le conozcan en parte. Los de menor esfera se entretienen sólo con lo inmediato y superficial; otros más caudalosos conocen diversos motivos de estimación; hasta que los mayores ingenios, los más doctos y prácticos en la facultad penetran al íntimo conocimiento de lo compuesto, complaciéndose más que todos en lo superior de sus méritos. Esto conocía Quintiliano cuando dijo: Aquel a quien agradare mucho Cicerón, ése crea que está aprovechado. Ille se profecisse sciat, cui Cicero valde placebit. Supone que el hallar sumo agrado en las obras insignes pertenece a los que más saben, y así, de sólo agradarnos de Cicerón, infiere sabiduría porque sin ella no se pondera tan alto mérito ${ }^{40}$.

Para Góngora no podía dejar de ser obvia la preferencia de Jáuregui por el discurso explícito. Bien podría tratarse, en última instancia, de la razón de su crítica al Orfeo en el soneto ya citado al inicio de este artículo. La correspondencia directa de fondo y forma en el poema de su crítico más enconado era también —como ya se ha visto- el escenario propicio para que el tema de la música órfica, con sus posibilidades catárticas, terminara seduciendo al autor mismo. Jáuregui, a pesar de las numerosas críticas tanto de claros como de oscuros, tuvo conciencia de haber hecho coincidir poética preceptiva y práctica poética en su poema narrativo de $1624^{41}$.

JORGE ZEPEDA

Corte, es el retiro en una soledad estudiosa; a la turbamulta de cortesanos que le disgusta, prefiere el círculo limitado de amigos escogidos, el cenáculo. De manera que, paradójicamente, este «menosprecio de Corte», generalmente sincero y sentido profundamente, desemboca en una especie de aristocraticismo exacerbado" (Don Luis de Góngora y Argote, pp. 519-520). Desde esta perspectiva, los ataques a Jáuregui son resultado de una dificultad de apreciación, “...porque los límites que lo separan de las posiciones opuestas - cultos y claros- son en ocasiones tan sutiles que, puestos en práctica, se desdibujan" (Melchora Romanos, "La poesía de Juan de Jáuregui en el fiel de la balanza”, Edad de Oro, 6, 1987, p. 262).

${ }^{40}$ Discurso poético, p. 128.

${ }^{41}$ Que el Discurso poético y el Orfeo eran una sola unidad queda claro si se recuerda que “...el Discurso carece de aprobaciones por darse las mismas en el Orfeo" (MelchoRa Romanos, Prólogo a la edición citada del Discurso poético, p. 21). 